\title{
EFFECTS OF COLCHICINE APPLICATION AND PLOIDY LEVEL ON FRUIT SECONDARY METABOLITE PROFILES OF GOLDENBERRY (PHYSALIS PERUVIANA L.)
}

\author{
ÇÖMLEKÇIOĞLU, N. ${ }^{*}-$ ÖZDEN, M. ${ }^{2}$ \\ ${ }^{I}$ Department of Horticulture, Faculty of Agriculture, Eskişehir Osmangazi University, \\ Eskişehir, Turkey \\ ${ }^{2}$ Faculty of Agricultural Sciences and Technologies, Niğde Ömer Halisdemir University, Niğde, \\ Turkey \\ *Corresponding author \\ e-mail: ncomlekcioglu@ogu.edu.tr; phone: +90-222-239-3750 fax: +90-222-324-2990 \\ (Received $7^{\text {th }}$ Aug 2019; accepted $28^{\text {th }}$ Nov 2019)
}

\begin{abstract}
The aim of this study was to investigate changes of phenolic accumulation and antioxidant potential of goldenberry fruits collected from diploid plants, under colchicine treatments of different doses and exposure time, including colchicine induced synthetic tetraploid plants. Three colchicine application methods were utilized; i) immersion of seeds in colchicine solution at concentrations of 0.0 , $0.6,0.9 \%$ for $24 \mathrm{~h}$ and $36 \mathrm{~h}$; ii) keeping germinated seeds (with $2-3 \mathrm{~mm}$ long roots) in a colchicine solution with concentrations of $0.6 \%$ and $0.9 \%$ for $24 \mathrm{~h}$ iii) incubation of seeds on semi solid nutrient medium containing $0.6 \%$ and $0.9 \%$ colchicine for 14 and 21 days. Total antioxidant activity of fruits varied according to the dose and exposure time of colchicine applications. The most important change was observed in the fruits of plants that turned tetraploid as a result of colchicine applications. Tetraploid fruits generally produced higher amounts of secondary compounds compared to diploid progenitors and their antioxidant capacity was also higher. However, the results show that polyploidization is important but cannot be generalized as a strategy to increase secondary metabolite production. It was determined that the relationship between total anthocyanin and total phenolic content with antioxidant capacity of fruits was significant and parallel. We suggest the use of the lowest colchicine concentration tested. $0.6 \%$ colchicine to enhance metabolite production cannot be generalized.
\end{abstract}

Keywords: tetraploid, anthocyanin, phenolic, flavonoid, antioxidant

\section{Introduction}

Goldenberry (Physalis peruviana L.) is a small fruit, belonging to the Solanaceae family. Recently it has gained much attention in our country and in the world, because of its nutritional, medicinal and industrial properties. Goldenberry is most important fruits that is recommended to be consumed as functional drinks and fruit due to high rates of water and oil soluble bioactive substances, vitamins and minerals (Ramadan Hassanien, 2011). Valdenegro et al. (2012) reported that goldenberry is a fruit rich in vitamin $\mathrm{C}$, carotenoids and phenolic compounds. In phytochemical studies, flavonoids, saponins and phenols which are the main compounds in goldenberry fruit extracts, were also determined (Arun and Asha, 2006). It has been reported that goldenberry has a high antioxidant capacity and synergistic effects of different antioxidants. In addition, high levels of phenolic compounds in fruit have been reported (Ramadan and Mörsel, 2003; Ramadan Hassanien, 2011). Phenolic compounds are important in terms of human health as well as their contribution to color, taste and aroma of fruits (Valdenegro, et al., 2012). It is desirable some chemicals in plants to have protective, preventive and therapeutic effects from various diseases in humans. 
Recently interest of researchers, in nutrient richness of fruits, vegetables and contain high levels of bioactive compounds that act as antioxidants, have been increasing. Plant breeders are trying to develop polyploid plants in order to increase the yield and certain useful fruit quality properties of the fruit. Polyploids have superior agronomic properties compared to diploids. An increase in the number of chromosomes could improve basic secondary metabolites and concentrations of preservatives (Gao et al., 1996; Głowacka et al., 2010; Hannweg et al., 2016; Nori et al., 2017). It has been reported that enzyme activity (Dhawan and Lavania, 1996; Lavania, 2005), secondary metabolites that are important for taste and flavor and biochemical profiles (Gao et al., 1996; Predieri, 2001; Urwin et al., 2007; Zhang et al., 2010; Carusoa et al., 2011; te Beest et al., 2012) in plants improved by polyploidy.

Numerous factors (abiotic and biotic) are directly effective on the biochemical pathways in plants and affect the metabolism of secondary metabolite products (Alkhsabah et al., 2018). Aina et al. (2019) stated that the levels of bioactive compounds and antioxidant activities of tomato fruits cultivated on different soil amendments showed strong relationship between the level of macronutrients in the soil and the level phenolics, flavonoids, beta-carotene and lycopene contents in tomato. Shafiq et al. (2019) reported that selenium content in garlic increased by sodium selenate application. A significant increase in total phenolic content, total flavonoid content and total antioxidant capacity was also observed in the garlic. It has been noted that gibberellic acid had a negative effect on the content of extract, flavonoids and ascorbic acid, while it had no effect on the anthocyanin level. The antioxidant activity determined by the DPPH assay depended on dose and the number of treatments was shown to decrease significantly with increasing application number. Gibberellic acid application had a significantly increased DPPH level compared to the control. The GA3 treatments were shown to have a significant influence on phenolic acid content (Kaplan et al., 2019).

In order to improve the quality of important medicinal compounds, the plants' natural secondary metabolite production potentials, aromatics can be artificially promoted and increased by experimental arrangements. These crops can hold a market value as functional food. The enhance nutrients in food crops is powerful strategy to overcome micronutrient deficiency.

The main purpose of this study were to determine the changes of total anthocyanin, phenolic, flavonoid contents, free radical scavenging capacity and total antioxidant activity of goldenberry fruits by colchicines $\left(\mathrm{C}_{22} \mathrm{H}_{25} \mathrm{NO}_{6}\right)$ application to the plants.

\section{Materials and methods}

This study was conducted in the University of Eskisehir Osmangazi (Eskisehir, TURKEY) laboratories and greenhous. Physalis peruviana cv. Golden Berry (average fruit diameter is 1-2 inch. Pulp is very flavorful and sweet) was used as plant material in this study. The treated seeds were sown into peat containing plastic seedling tray in the 1st week of March. 45 days old (at 4-5 true leaf stage) seedlings (Fig. 1) were transplanted to peat containing pots $(15 \mathrm{~L})$ at the end of May in plastic greenhouse.

All plants were irrigated with drip irrigation system (Fig. 2) and fertilized with $13 \mathrm{~g}$ of 15: 8: 25: 3.5 nitrogen: phosphorus: potassium: magnesium oxide per plant. During the growing season, the average temperature of greenhouse varied between $14-18{ }^{\circ} \mathrm{C}$ at night and $22-30{ }^{\circ} \mathrm{C}$ at daytime. 


$$
\text { - } 291 \text { - }
$$

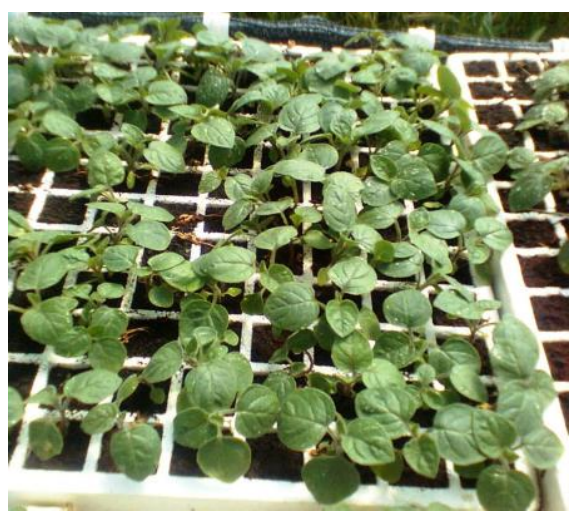

Figure 1. Seedling at planting stage

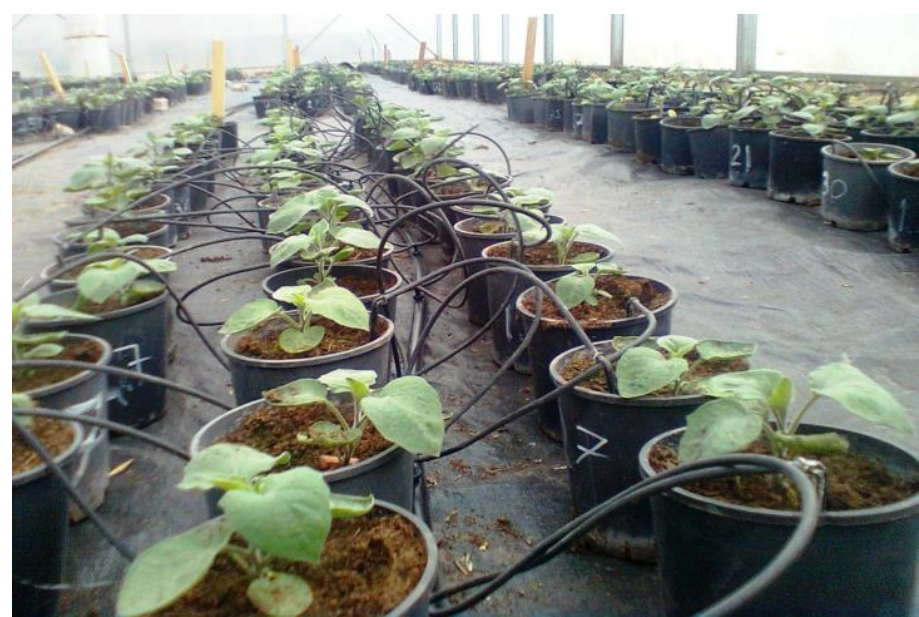

Figure 2. Plants grown in pots and irrigated by drip irrigation system

Colchicine at different doses and exposure times were applied to goldenberry seeds by different methods. Diploid plants that were not treated were evaluated as control. As a result of the applications, chromosomes of some plants were doubled (tetraploid; chromosomes were determined by flowcytometry, Comlekcioglu and Ozden, 2019). Fruits of plants in different application groups were used as material in this study.

Colchicine applications; i) keeping the seeds in colchicine solution (Fig. 3A) at 0.0 (T11), 0.6, 0.9\% concentration for $24 \mathrm{~h}$ and $36 \mathrm{~h}$ (T1, T2, T3 and T4); ii) keeping germinated seeds (Fig. 3B) with $2-3 \mathrm{~mm}$ long roots in colchicine solution at $0.6 \%$ (T9) and $0.9 \%$ (T10) concentrations for $24 \mathrm{~h}$; and iii) incubation of seeds on semi solid Murashige and Skoog (MS, 1962) medium (Fig. 3C) supplemented with colchicine at $0.6 \%$ and $0.9 \%$ concentrations for 14 and 21 days (T5, T6, T7 and T8).

Twenty seeds for each treatment, with three replications were used. Untreated diploid plants grown from untreated seeds were used as control. Ten plants (Fig. 4) with tree replication had been examined within a treatment for the evaluation of phenolic accumulation and antioxidant potential of fruits.

Fruits of plants in different application groups were harvested at full maturity (Fig. 5) and fruit weights were determined.

The doses and duration of colchicine applications and application methods are presented in Table 1. 


$$
\text { - } 292 \text { - }
$$
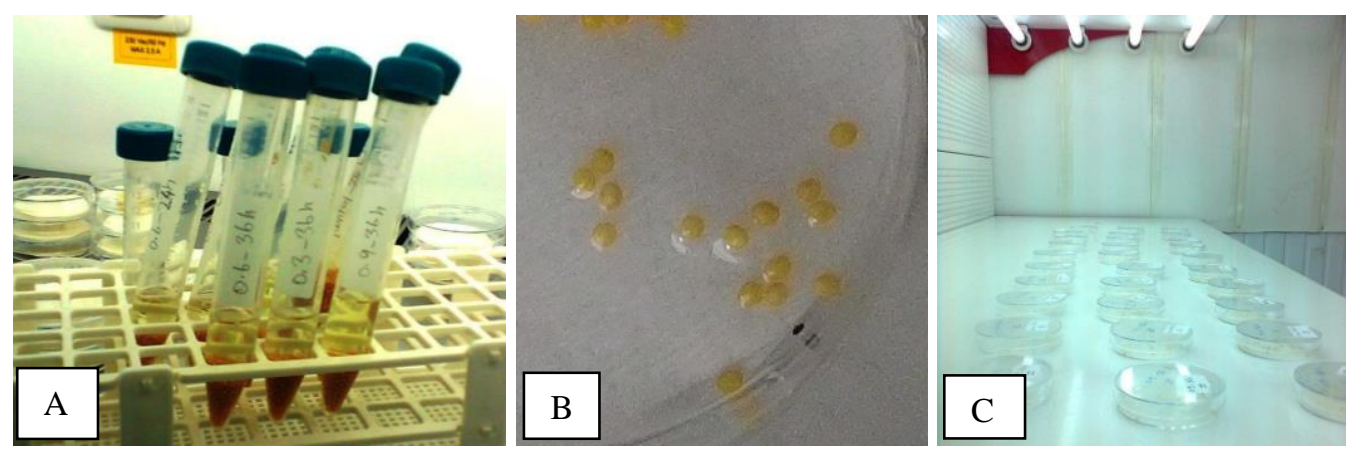

Figure 3. Colchicine application at different doses and exposure time to seeds by different methods. A; keeping the seeds in colchicine solution, B; keeping germinated seeds in colchicine solution C) incubation of seeds on colchicines contained semi solid MS medium

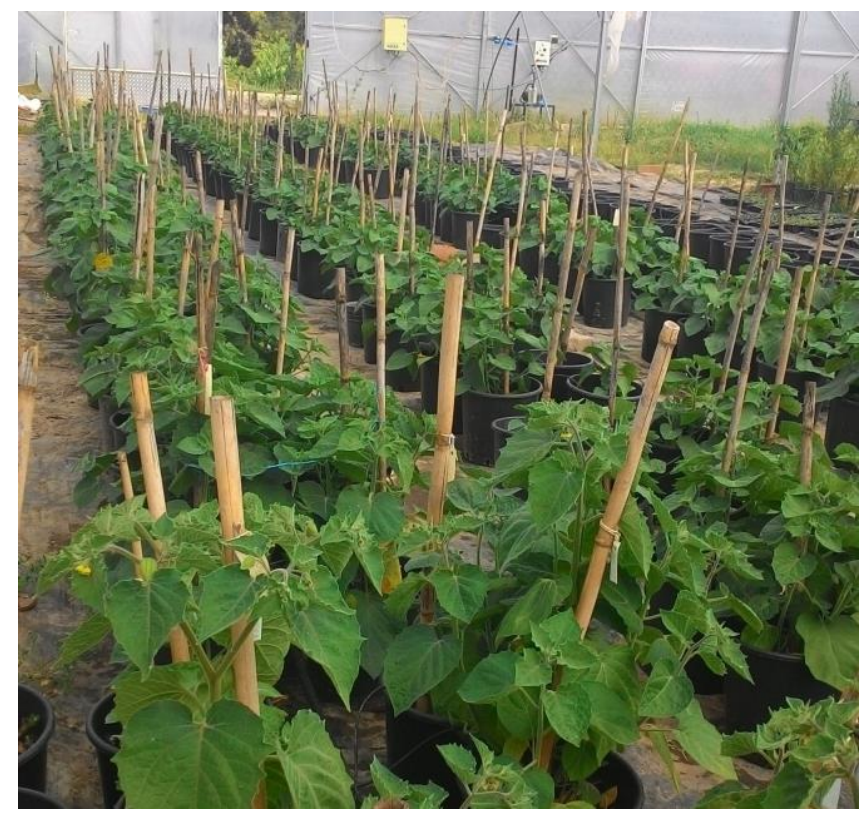

Figure 4. An appearance of growing plants in the greenhouse

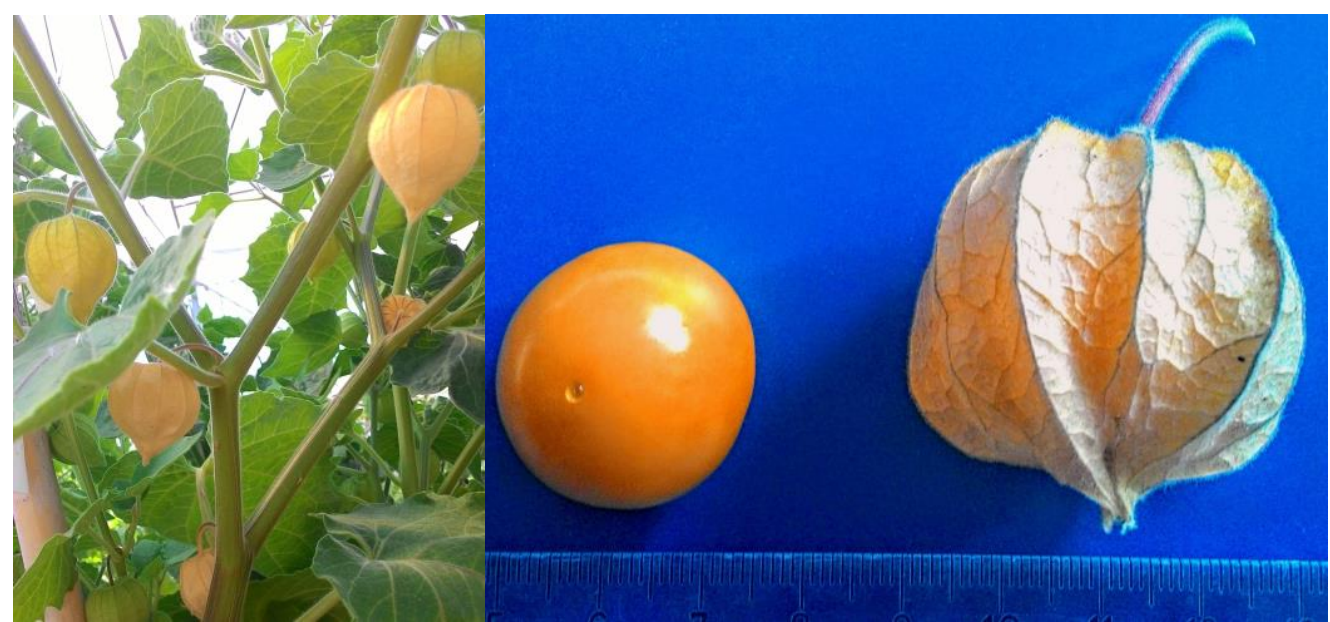

Figure 5. Mature fruits used for evaluations phenolic accumulation and antioxidant potential 
Table 1. Colchicine application doses, exposure times and application methods

\begin{tabular}{c|c|c|c}
\hline Treatments & Doses \% & Exposure times & Aplication methods \\
\hline T1 & 0.6 & $24 \mathrm{~h}$ & Seed \\
\hline T2 & 0.6 & $36 \mathrm{~h}$ & Seed \\
\hline T3 & 0.9 & $24 \mathrm{~h}$ & Seed \\
\hline T4 & 0.9 & $36 \mathrm{~h}$ & MS medium \\
\hline T5 & 0.6 & $14 \mathrm{~d}$ & MS medium \\
\hline T6 & 0.6 & $21 \mathrm{~d}$ & MS medium \\
\hline T7 & 0.9 & $14 \mathrm{~d}$ & Germinated seed \\
\hline T8 & 0.9 & $21 \mathrm{~d}$ & Germinated seed \\
\hline T9 & 0.6 & $24 \mathrm{~h}$ & $24 \mathrm{~h}$ \\
\hline T10 & 0.9 & \multicolumn{3}{|c}{ Tetraploid plants - Colchicine induced } \\
\hline T11 & \multicolumn{3}{|c}{}
\end{tabular}

\section{Extraction of fruit samples}

For extraction of the samples, the fruits were mashed in a cold blender. The $25 \mathrm{~g}$ homogenate was macerated in darkness for $24 \mathrm{~h}$ in $100 \mathrm{ml}$ of ethanol containing $0.1 \%$ $\mathrm{HCl}$. The extracts were then filtered through Whatman No.1 filter paper under vacuum and extraction was continued with the same solvent until the pulp was colorless. $50 \mathrm{ml}$ of the extract was separated and used to determine the total amount of anthocyanin. The other $50 \mathrm{ml}$ of the extraction was concentrated on a rotary evaporator by evaporating ethanol at $50{ }^{\circ} \mathrm{C}$ and used to determine total phenolic compounds and total flavonoids.

\section{Determination of total anthocyanins (TA)}

TA contents of the extracts were determined by $\mathrm{pH}$-differential method (Giusti and Wrolstad, 2001). According to this method, fruit extracts were incubated in $0.025 \mathrm{M}$ $\mathrm{KCl}$ buffer ( $\mathrm{pH} 1.0$ ) and $0.4 \mathrm{M} \mathrm{CH}_{3} \mathrm{COONa}$ buffer ( $\mathrm{pH} 4.5$ ) for $15 \mathrm{~min}$ at room temperature. Absorbance was measured at 520 and $700 \mathrm{~nm}$ and the absorbance values were found by Equation 1:

$$
\mathrm{A}=(\mathrm{A} \lambda 520-\mathrm{A} \lambda 700) \mathrm{pH} 1.0-(\mathrm{A} \lambda 520-\mathrm{A} \lambda 700) \mathrm{pH} 4.5
$$

According to Wrolstad (1976), the total amount of anthocyanin was calculated as follows:

$$
\mathrm{TA}\left(\mathrm{mg} \mathrm{kg}^{-1}\right)=\mathrm{A} \times \mathrm{MA} \times \mathrm{DF} \times 1000 / \varepsilon \times 1
$$

A: absorbance, MA: Molecular weight of Malvidin-3-O-glucoside; $493.5 \mathrm{~g} \mathrm{~mol} \mathrm{l}^{-1}$, DF: Dilution factor, $\varepsilon$, molar absorption coefficient $(28,000)$.

\section{Determination of total phenolic compounds (TP)}

TP contents of goldenberry fruit extracts were determined by modification of Slinkard and Singleton (1977) method. $2.37 \mathrm{ml} \mathrm{H}_{2} \mathrm{O}$ and $0.15 \mathrm{ml}$ Folin-Ciocalteu's reagent were added to fruit extract $(0.03 \mathrm{ml})$ respectively. After about $8 \mathrm{~min}, \mathrm{Na}_{2} \mathrm{CO}_{3}$ 
$(0.45 \mathrm{ml})$ was added and the contents were mixed thoroughly. After the mixtures were allowed to stand at room temperature for $30 \mathrm{~min}$, the absorbance measured at $750 \mathrm{~nm}$ with spectrophotometer. The concentrations of the total phenolic compounds in the fruit extracts were expressed as $\mathrm{mg}$ of gallic acid equivalent (GAE) per $\mathrm{kg}$ of fresh weight $(\mathrm{FW})$.

\section{Determination of total flavonoids (TF)}

Total flavonids contents of the samples were determined by aluminum chloride colorimetric method applied by Zhishen et al. (1999). $4 \mathrm{ml} \mathrm{H} 2 \mathrm{O}, 5 \mathrm{ml} \mathrm{0.3 \%} \mathrm{NaNO}_{2}$ were added to $1 \mathrm{ml}$ of fruit extract or standard catechin solution $(20,40,60,80$, $100 \mathrm{mg} \mathrm{l}^{-1}$ ). After $5 \mathrm{~min}, 0.3 \mathrm{ml}$ of $10 \% \mathrm{AlCl}_{3}$ was added to the mixture. Then at $6 \mathrm{~min}$, $2 \mathrm{ml}$ of $1 \mathrm{M} \mathrm{NaOH}$ was added to the mixture and the total volume was completed to $10 \mathrm{ml}$ with $\mathrm{H}_{2} \mathrm{O}$. The solution was mixed thoroughly. The absorbance measured at $510 \mathrm{~nm}$ with spectrophotometer. Total flavonide contents of the samples were given in $\mu \mathrm{g}$ catechin equivalent (CE) per $\mathrm{g}$ of $\mathrm{FW}$.

\section{Determination of total antioxidant activity $(A A)$}

Antioxidant capacities of ethanolic extracts were determined by the 1,1-diphenyl-2picrylhydrazyl (DPPH) free radical scavenging, Ferric Reducing Antioxidant Power (FRAP), and Phosphomolybdenum (Mo) methods.

The free radical scavenging capacity of the samples were measured by the 1,1diphenyl-2-picrylhydrazyl (DPPH) method according to Blois (1958). $2.9 \mathrm{ml}$ of DPPH $(0.1 \mathrm{mM})$ was added to fruit extracts of various concentrations obtained by dilution with ethanol. After $15 \mathrm{~min}$, the absorbance of the mixture was measured at $517 \mathrm{~nm}$. The capacity of each application to reduce free radicals of the sample is determined in $\%$ by Equation 2:

$$
\text { DPPH Inhibition }(\%)=[(\mathrm{Ac}-\mathrm{As}) / \mathrm{Ac} \times 100]
$$

Ac; control absorbance, As; absorbance of samples.

The determination of total antioxidant capacities of the samples was done by Phosphomolybdenum (MO) and Ferric Reducing Antioxidant Power (FRAP) methods. As described by Prieto et al. (1999) $0.3 \mathrm{ml}(20 \mu \mathrm{g} / \mathrm{ml})$ sample extract was mixed with $1 \mathrm{ml}$ reagent solution $(0.6 \mathrm{M}$ sulfuric acid, $28 \mathrm{mM}$ sodium phosphate, $4 \mathrm{mM}$ ammonium molybdate) and incubated for $90 \mathrm{~min}$ at $95^{\circ} \mathrm{C}$. After the samples were quickly cooled in crushed ice to room temperature the absorbance at $695 \mathrm{~nm}$ was measured. The obtained values were expressed as $\mu \mathrm{g}$ ascorbic acid equivalent (AE) per ml extract by using the ascorbic acid standard curve prepared at different concentrations (20-250 mg ml${ }^{-1}$ ) of ascorbic acid used as positive control.

Ferric Reducing Antioxidant Power (FRAP) were determined according to Oyaizu (1986). $1 \mathrm{ml}$ ethanolic fruit extracts $(20 \mu \mathrm{g}$ ml-1), $2.5 \mathrm{ml}$ phosphate buffer solution $(0.2 \mathrm{M}$ $\mathrm{pH}$ : 6.6) and $2.5 \mathrm{ml} 1 \%$ potassium ferricyanate $\left(\left[\mathrm{K}_{3} \mathrm{Fe}(\mathrm{CN})\right]_{6}\right)$ solution were mixed. The mixture was incubated for $20 \mathrm{~min}$ at $50{ }^{\circ} \mathrm{C}$ and then cooled rapidly in crushed ice. Then, $2.5 \mathrm{ml}$ of $10 \%$ trichloroacetic acid (TCA) was added to the mixtures and centrifuged at $2000 \mathrm{rpm}$ for $15 \mathrm{~min}$. The upper layer of the supernatant $(2.5 \mathrm{ml})$ was diluted with distilled water and $0.5 \mathrm{ml}$ of $0.1 \% \mathrm{FeCl}_{3}$ was added. Then the absorbance was read spectrophotometrically at $700 \mathrm{~nm}$ against water blank. Using the calibration curve of 
Butylhydroxytolune (BHT) $(20-250 \mathrm{mg} / \mathrm{ml})$ at different concentrations used as positive control, the antioxidant activity of the samples was expressed as $\mu \mathrm{g}$ BHT per ml extract.

In the study, all analyzes were measured with three replications. The data presented here are the mean of three replications with \pm SEM. The significance of the mean differences was determined by the least significant differences (LSD) test using the general linear model (GLM) at $P<0.05$.

\section{Results and discussion}

The main objective of this study was to determine the effects of different doses and exposure times colchicine applications, resulted with or without chromosome doubling, on secondary metabolite profiles in goldenberry fruits.

The fruits of plants from different colchicine treatment groups were harvested at commercial maturity stage and 100 fruit weights were determined (Fig. 6).

In the study, 100 of the control group fruits were weighed as $356.58 \mathrm{~g}$, followed by the fruits of T6 application group $(367.65 \mathrm{~g})$. The heaviest fruits were obtained from tetraploid plants in the T12 treatment group (411.25 g), while the fruit from all other colchicine treatment groups remained low in weight relative to the control (Fig. 6).

Total anthocyanin (TA), total phenolic compounds (TP) and total flavonoid content (TF) of the fruits of the plants treated with different colchicine showed significant differences.

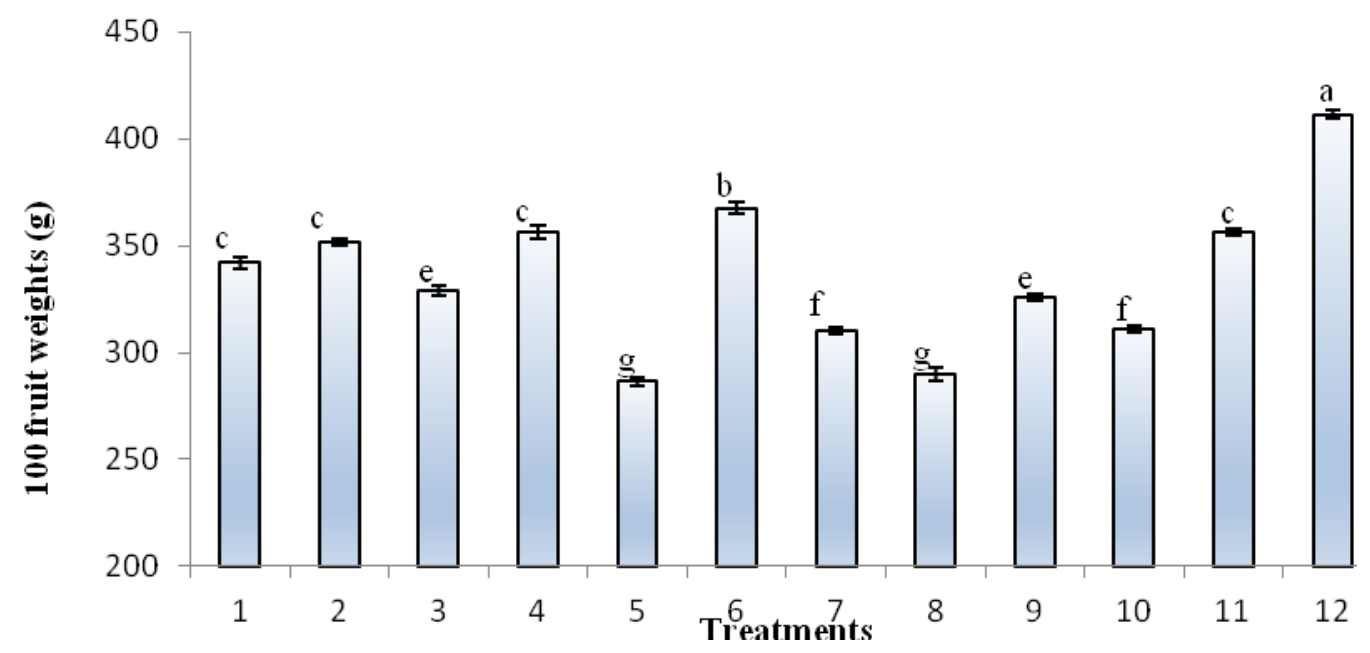

Figure 6. Average weights of 100 fruit measured from different colchicine treatment groups. Different letters on the columns are expressed statistical difference at $P \leq 0.05$ determined by the LSD test

TA content of ethanolic extracts of the goldenberry fruit is given in Figure 7. According to the analysis results, the highest (559.60 mg malvidin-3-glucoside $\mathrm{kg}^{-1} \mathrm{FW}$ ) was measured in tetraploid plant fruits, followed by the amount of anthocyanin (539.32 $\mathrm{mg} \mathrm{kg}^{-1}$ ) in T9 fruits. The anthocyanin contents of the tetraploid samples were found to be significantly higher than the control group. Except for the T9 application, the effect of all applications on the anthocyanin contents of the fruits was measured less than the control. TA value of tetraploid fruits increased by $9.1 \%$ compared to diploid. 


$$
\text { - } 296 \text { - }
$$

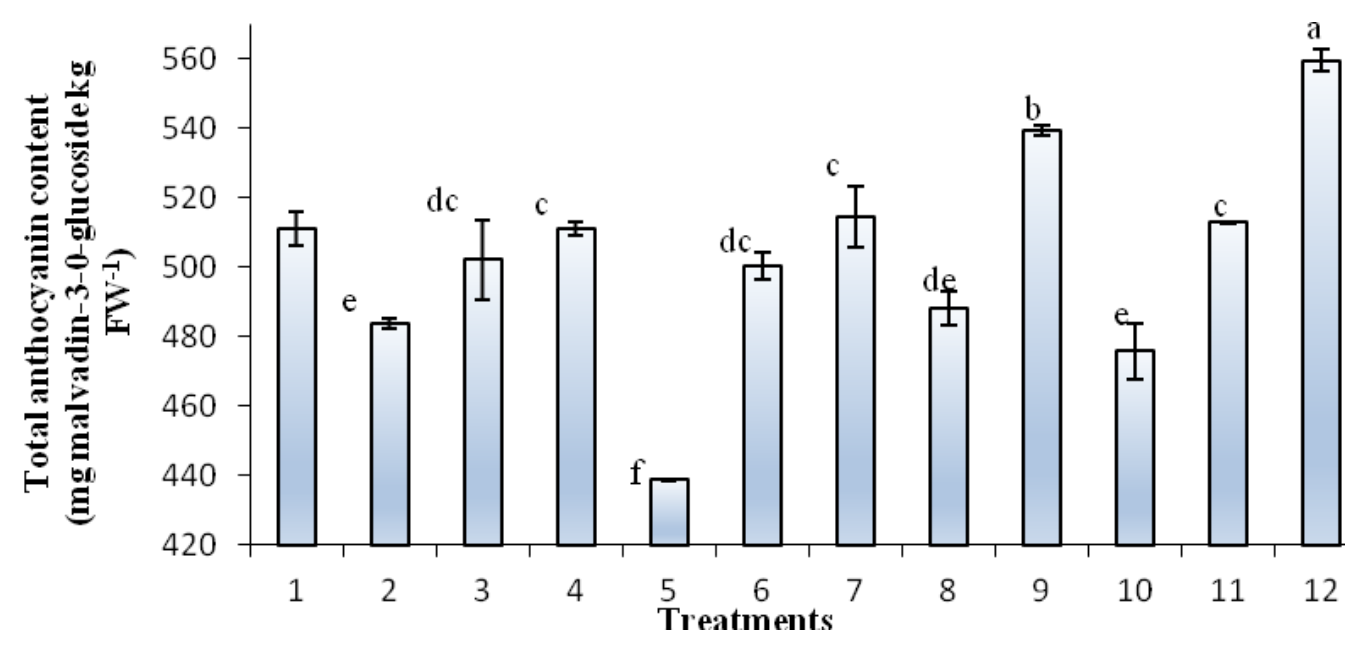

Figure 7. Total anthocyanin content (mg malvidin-3-0-glucoside $\mathrm{kg}^{-1} \mathrm{FW}$ ) of goldenberry fruits from different colchicine treatment groups. Different letters on the columns are expressed statistical difference at $P \leq 0.05$ determined by the LSD test

TP contents of fruit extracts were expressed as mg GAE kg fresh weight using the gallic acid standard curve (Fig. 8). According to the results of the analysis carried out in the goldenberry fruits under the effect of different colchicine applications, the highest TP content was measured in the fruits of tetraploid plants (1128 $\left.\mathrm{mg} \mathrm{GAE} \mathrm{kg}^{-1} \mathrm{FW}\right)$. The tetraploid fruits were follow by $\mathrm{T} 1\left(1079.0 \mathrm{mg} \mathrm{GAE} \mathrm{kg}^{-1} \mathrm{FW}\right) \mathrm{T} 11$ and T9 applications (Fig. 8).

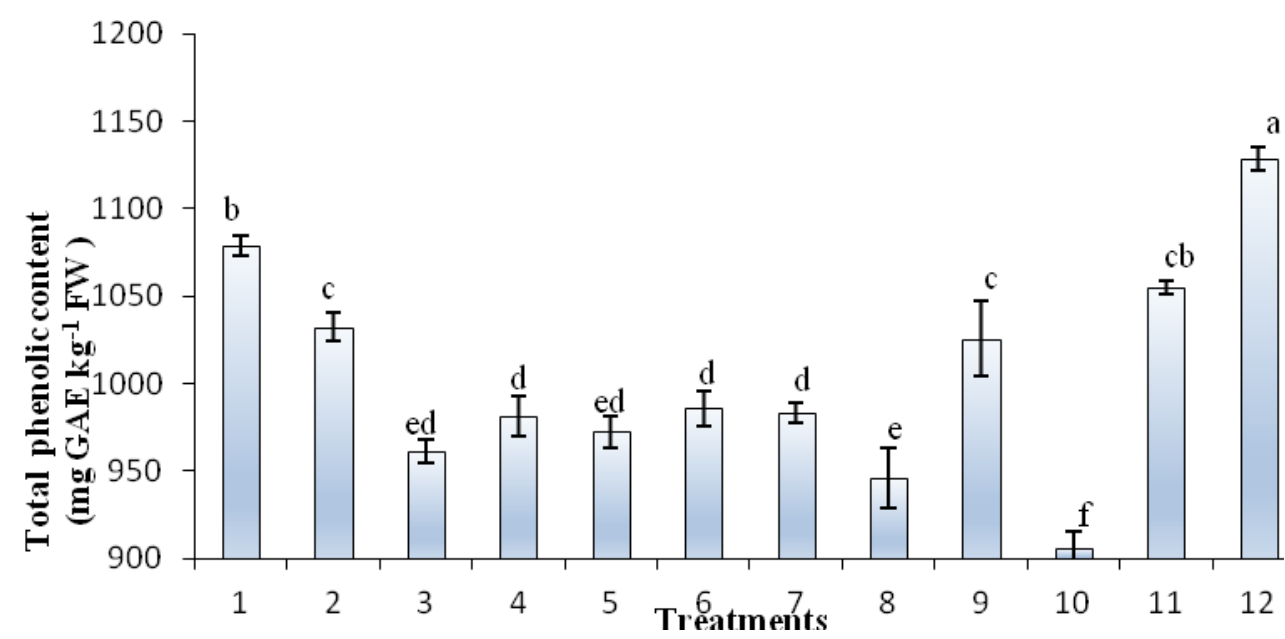

Figure 8. Total phenolic content ( $m g$ GAE $\mathrm{kg}^{-1} \mathrm{FW}$ ) of goldenberry fruits from different colchicine treatment groups. Different letters on the columns are expressed statistical difference at $P \leq 0.05$ determined by the LSD test

In the study, tetraploid fruits phenolic compounds were also found to be richer than control group as in the anthocyanin content. Except for T1 and T12 applications, the effects of other colchicine applications on the TP content of the fruits were limited compared to the control group. 
According to the analysis results, TF contents of fruits ranged from $579.38 \mu \mathrm{g} \mathrm{CE} \mathrm{g}^{-1}$ FW (T10) to $1282.02 \mu \mathrm{g} \mathrm{CE} \mathrm{g}^{-1} \mathrm{FW}$ (T2). Unlike TA and TP, the increase in TF was found to be independent of chromosome doubling. The highest value was obtained from T2 application. This value was followed by flavonoid contents measured in T9 (961.84 $\mu \mathrm{g}$ $\mathrm{CE} \mathrm{g}^{-1} \mathrm{FW}$ ) and $\mathrm{T} 5\left(906.57 \mu \mathrm{g} \mathrm{CE} \mathrm{^{-1 }} \mathrm{FW}\right)$ fruits. Fruits from T2 and T12 (tetraploid fruits) treatments had $88.7 \%$ and $21.95 \%$ respectively higher TF content than diploid progenitor control group. Tetraploid fruits showed an increasing tendency compared to diploids. Except for T3 and T10 treatments, the effects of colchicine applications on the TF contents of fruits were found to be significant compared to the control (Fig. 9).

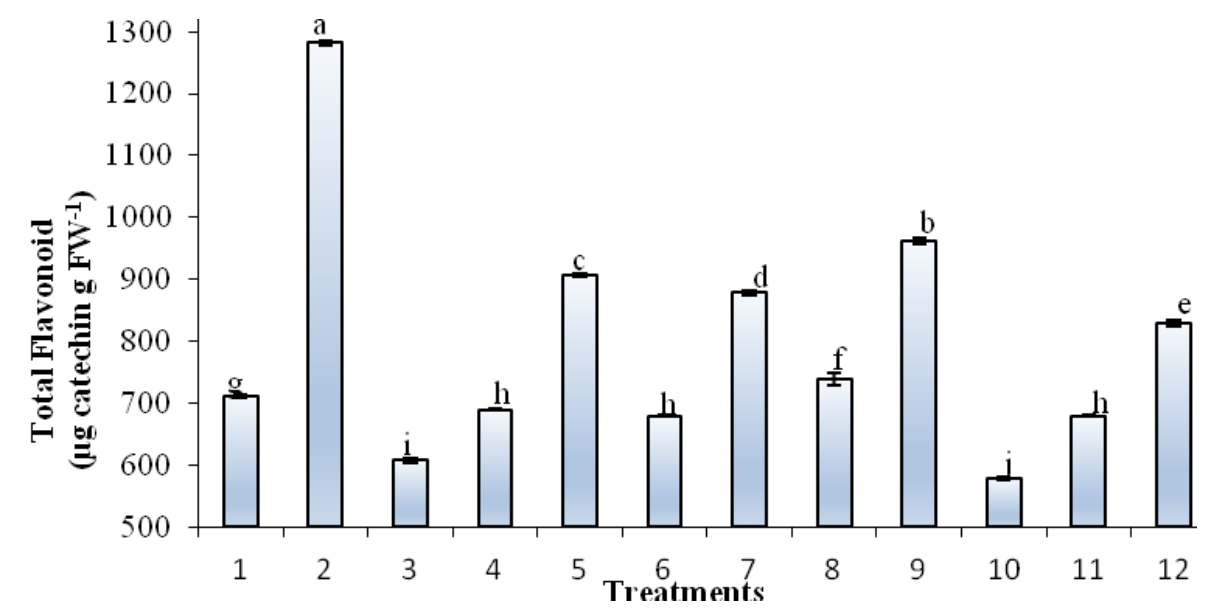

Figure 9. Total flavonoid content ( $\mu \mathrm{g} C E \mathrm{~g}^{-1} \mathrm{FW}$ ) of goldenberry fruits from different colchicine treatment groups. Different letters on the columns are expressed statistical difference at $P \leq 0.05$ determined by the LSD test

The free radical scavenging capacity of fruit samples was determined by using a synthetic, stable free radical molecule of 1,1-diphenyl-2-picrylhydrazyl (DPPH) (Blois, 1958).

The ethanolic extracts of the fruits of the plants with different colchicine treatment groups were found to have different free radical scavenging capacity, and the highest inhibition capacity was determined in fruit of tetraploid plants.

When DPPH free radical scavenging capacity was compared between the application groups, the highest value $(65.96 \%)$ compared to the control $(50.82 \%)$ was measured in tetraploid fruits (Fig. 10).

The increase rate of free radical scavenging capacity in tetraploid fruits was $29.79 \%$ compared to diploid progenitors. These results show that antioxidant capacity (DPPH inhibition) in fruit was increased rather associated with chromosome doubling, as well as increasing TA and TP values. The effectiveness of other treatments was limited compared to the control and was found to be statistically insignificant. Results of total antioxidant activity of the samples determined by phosphomolybdenum method are given in Figure 11. The highest antioxidant capacity of fruit samples $\left(130.03 \mu \mathrm{g} \mathrm{AE} \mathrm{ml} l^{-}\right.$ 1 extract) was determined in tetraploid (T12) fruit samples.

As in the DPPH results, T12 was followed by T8 (116.57 $\mu \mathrm{g} \mathrm{GAE} \mathrm{ml}^{-1}$ extract) and

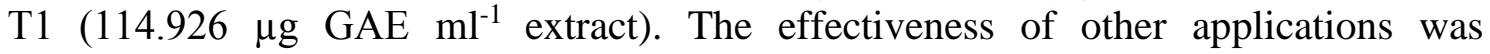
considered to be limited or statistically insignificant compared to the control. 


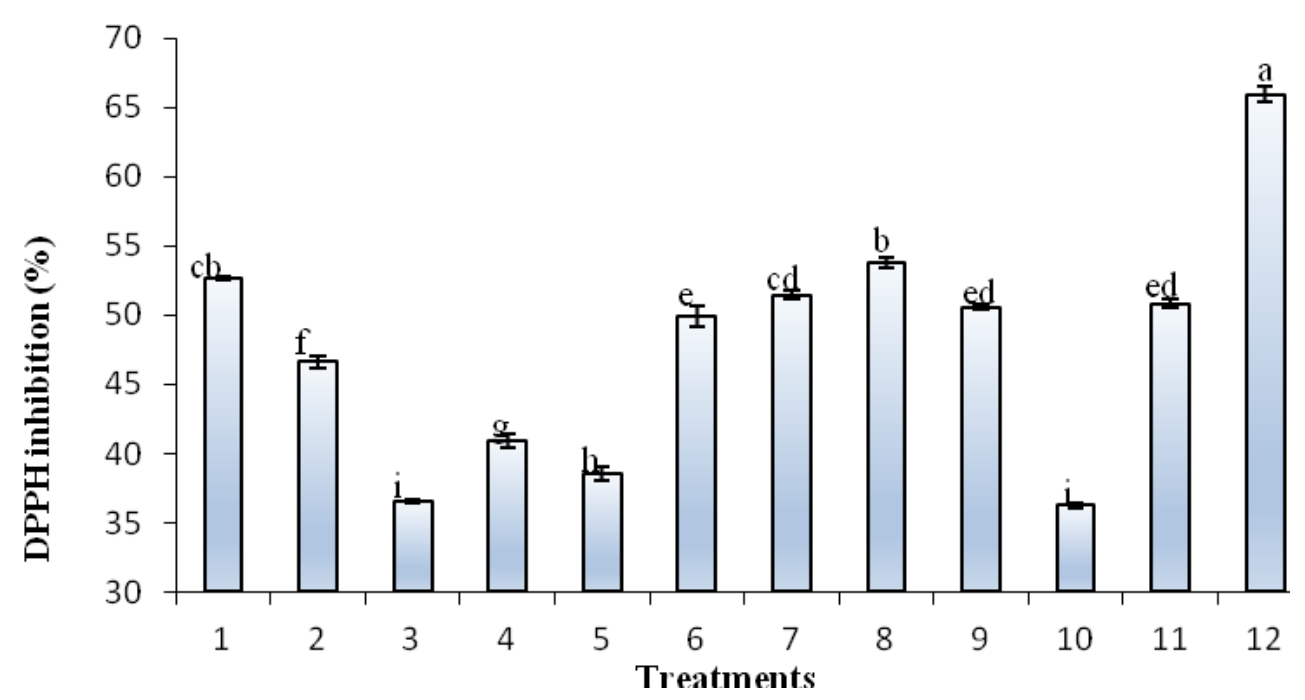

Figure 10. DPPH free radical scavenging activity (\%) of goldenberry fruit extracts from different colchicine treatment groups. Different letters on the columns are expressed statistical difference at $P \leq 0.05$ determined by the LSD test

The total antioxidant capacity of the fruits determined by the MO method was similar to the values determined by the DPPH method. Although different colchicine applications cause increasing or decreasing effects compared to control fruits, it was determined that the most important increase was obtained due to polyploidy (Fig. 11).

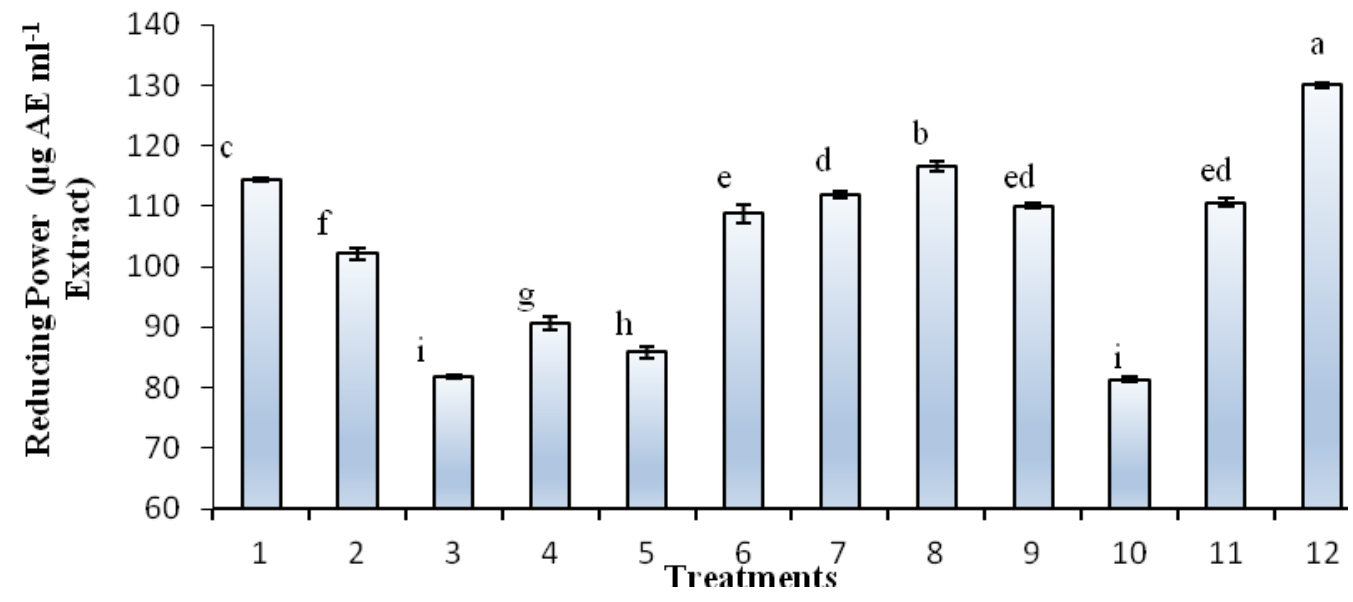

Figure 11. Antioxidant activity ( $\mu \mathrm{g} A E \mathrm{ml}^{-1}$ extract) of goldenberry fruit extracts from different colchicine treatment groups determined by phosphomolybdenum method (reduction of Mo-VI to $M o-V)$. Different letters on the columns are expressed statistical difference at $P \leq 0.05$ determined by the LSD test

When the antioxidant capacity of ethanolic fruit extracts from different colchisin applications were evaluated, the highest value was determined as $218.85\left(\mu \mathrm{g} \mathrm{BHT} \mathrm{ml}^{-1}\right.$ extract) in T2 application fruit samples. This was followed by T1 (107.35 $\mu \mathrm{g} \mathrm{BHT} \mathrm{ml}^{-1}$ extract), and fruit extracts from $\mathrm{T} 9$ treatment (83.21 $\mu \mathrm{g} \mathrm{BHT} \mathrm{ml}^{-1}$ extract) (Fig. 12). 


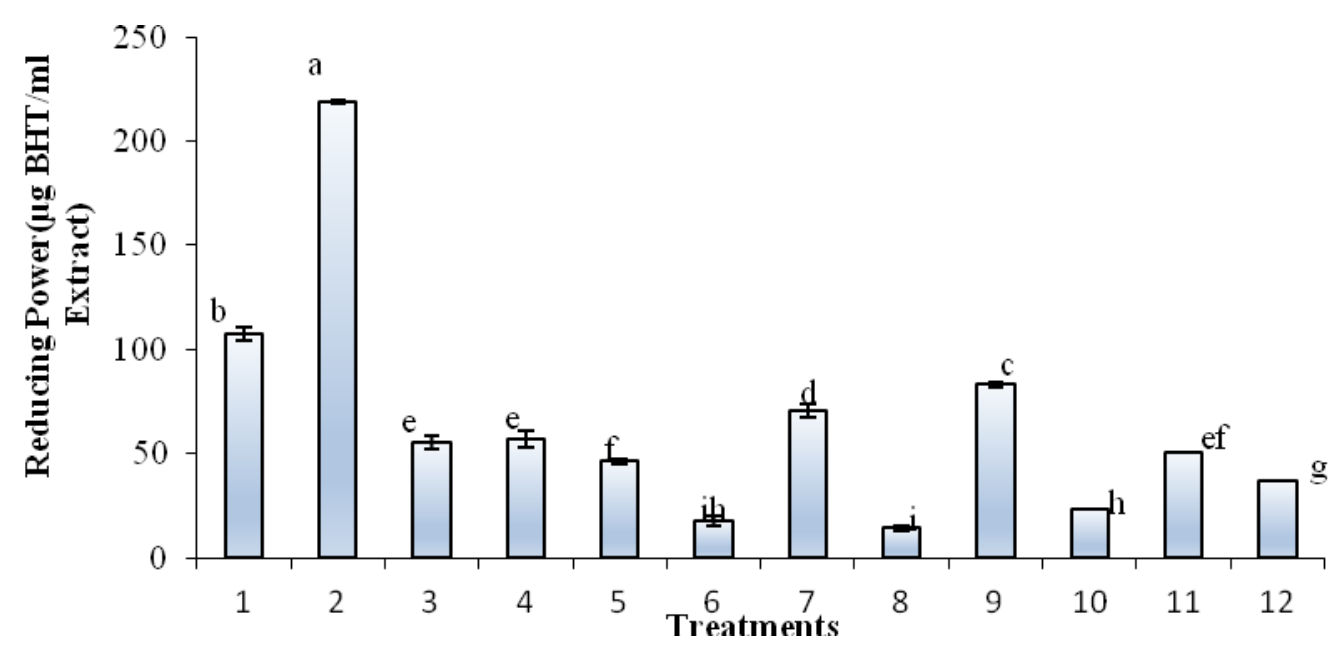

Figure 12. Ferric Reducing Antioxidant Power (FRAP) ( $\mu \mathrm{g} B H T \mathrm{ml}^{-1}$ extract) of goldenberry ethanolic fruit extracts from different colchicine treatment groups. Different letters on the columns indicate the difference at $P \leq 0.05$ level determined by the LSD test

According to the data obtained from the research, the secondary metabolite contents of diploid, colchicine treated and tetraploid plants showed significant differences. The amount of anthocyanin and phenolic compounds of tetraploid fruits was higher than diploid and colchicine treated fruits.

Different colchicine applications significantly affected the TA content of fruits $(P \leq 0.05)$.

Among colchicine applications that could not induce chromosomes doubling, TA increases were determined in T9 compared to control. However, the greatest increase in TA content was determined by the increase in ploidy level. The highest TA $\left(559.59 \mathrm{mg} \mathrm{kg}^{-1}\right.$ ) was reached in the tetraploid fruits (Fig. 7). TA value of tetraploid fruits increased by $9.1 \%$ compared to diploid. As a result of colchicine applications, the change in total phenolic content of fruits was found to be significant. Total phenolic contents ranged from $905.77 \mathrm{mg} \mathrm{GAE} \mathrm{kg}^{-1}$ fresh weight to $1128.00 \mathrm{mg} \mathrm{GAE} \mathrm{kg}^{-1}$ fresh weight (Fig. 8). As in TA content, the highest value was also determined in tetraploid fruits. It was determined that the effects of different colchicines applications on the total flavonoid content of the fruits were significant. Total flavonoids of the fruits ranged from $579.38 \mu \mathrm{g} \mathrm{KE} \mathrm{g-1} \mathrm{fresh} \mathrm{weight} \mathrm{(T10)} \mathrm{to} 1282.02 \mu \mathrm{g} \mathrm{KE} \mathrm{g-1} \mathrm{fresh} \mathrm{weight} \mathrm{(T2)}$ (Fig. 9). Tetraploids showed an increasing tendency compared to diploid fruits. Colchicine application also caused an increase in TF compared to control, except T3 and T10 treatments. Among applications T2 fruits showed 88.7\%, and T12 (tetraploid) fruits $21.95 \%$ higher TF contents than control (diploid progenitor) (Fig. 8).

The antioxidant capacities of the samples, expressed as DPPH scavenging (\%) extract concentrations, were strongly influenced by colchicine applications. Increases and decreases were determined in different treatments compared to the control and tetraploid fruits (T12) had higher DPPH sweeping capacity than all other treatments (Fig. 10). The increasing rate in tetraploid fruits was $29.79 \%$ compared to diploid progenitor (Fig. 10). These results show that antioxidant capacity (DPPH inhibition) in fruit is increased in association with chromosome doubling, as in the increase in TA and TP values. In this study, total antioxidant capacity of the fruits determined by FRAP 
method decreased in contrast to increasing ploidy level. FRAP values were the highest in $\mathrm{T} 2\left(218.85 \mu \mathrm{g} \mathrm{BHT} \mathrm{ml}{ }^{-1}\right.$ extract) and T1 (107.35 $\mu \mathrm{g} \mathrm{BHT} \mathrm{ml}^{-1}$ extract).

As a result of this research, total phenolic and flavonoid content of fruits of plants with different colchicine application and different ploidy level the samples swept the DPPH free radical and the Mo (VI) (Fig. 11) ions were reduced. The results presented in this study clearly indicate that the antioxidant activity was correlated with the phenolic content of fruits own.

In addition T3, T4, T7 and T9 treatments showed significantly higher antioxidant capacity than both diploid and tetraploid fruits with FRAP method (Fig. 12). Consistent with the results of this research, according to Özden and Özden (2014) research on 14 different fruit varieties, it is stated that antioxidant properties of fruits are related to total phenolic content of fruits.

\section{Conclusions}

Oxidation, a side effect of numerous physiological and biochemical processes in the human body, is an important and natural process. In many ways it is good, but it has the potential to be bad. In case of high oxidation, the body's aging and rusting rate increases. Damage caused by free radicals can be prevented by free radicals bounding to an antioxidant and swept from the body without damaging other cells. Therefore, high antioxidant content of foods slows down the aging process. The quantity of important medicinal compounds, aromatics, natural secondary metabolite production and antioxidant potentials of the plants can be artificially enhanced by experimental arrangements. Caruso et al. (2013) reported that tetraploid genotypes of Solanum bulbocastanum exhibited either a similar or a lower phenylpropanoids, tryptophan, tyrosine and chaconine content compared to the diploid parent.

Although fruits of tetraploid plants generally produce higher amounts of secondary compounds than diploid progenitors and have higher antioxidant capacities, our results show that polyploidization is important as a strategy to increase secondary metabolite production, but it cannot be generalized. It was determined that the relationship between total anthocyanin and total phenolic contents and antioxidant capacity of fruits was significant and parallel. Finally, colchicine can be used for polyploidization as strategy and we suggest the use of the lowest colchicine concentration tested, $0.6 \%$ colchicine to enhance metabolite production cannot be generalized.

Acknowledgement. This article is a part of research project No. 2013-191 supported by the Scientific Research Projects Commission of Eskisehir Osmangazi University.

\section{REFERENCES}

[1] Alkhsabah, I. A., Alsharafa, K. Y., Kalaji, H. M. (2018): Effects of abiotic factors on internal homeostasis of Mentha spicata leaves. - Applied Ecology and Environmental Research 16(3): 2537-2564.

[2] Aina, O. E., Amoo, S. O., Mugivhısa, L. L., Olowoyo, J. O. (2019): Effect of organic and inorganic sources of nutrients on the bioactive compounds and antioxidant activity of tomato. - Applied Ecology and Environmental Research 17(2): 3681-3694. 
[3] Arun, M., Asha, V. V. (2006): Preliminary studies on antihepatotoxic effect of Physalis peruviana Linn. (Solanaceae) against carbon tetrachloride induced acute liver injury in rats. - Journal of Ethnopharmacology 111: 110-114.

[4] Blois, M. S. (1958): Antioxidant determinations by the use of a stable free radical. Nature 181: 1199-1200.

[5] Caruso, I., Lepore, L., De Tommasi, N., Dal Piaz, F., Aversano, R., Garramone, R., Carputo, D. (2011): Secondary metabolite profile in induced tetraploids of wild Solanum commersonii Dun. - Chemistry \& Biodiversity 8: 2226-2237.

[6] Caruso, I., Dal Piaz, F., Malafronte, N., De Tommasi, N., Aversano, R., Zottele, C. W., Scarano, M. T., Carputo, D. (2013): Impact of ploidy change on secondary metabolites and photochemical efficiency in Solanum bulbocastanum. - Natural Product Communications 8: 1387-1392.

[7] Comlekcioglu, N., Ozden, M. (2019): Polyploid induction by colchicine treatment in goldenberry (Physalis peruviana), and effects of polyploidy on certain traits. - The J. Anim. Plant Sci. 29(5): 1336-1343.

[8] Dhawan, O. E., Lavania, U. C. (1996): Enhancing the productivity of secondary metabolites via induced polyploidy: a review. - Euphytica 87: 81-89.

[9] Gao, S. L., Zhu, D. N., Ca1z, H., Xu, D. R. (1996): Autotetraploid plants from colchicinetreated bud culture of Salvia miltiorrhiza Bge. - Plant Cell, Tissue and Organ Culture 47: 73-77.

[10] Głowacka, K., Jezowski, S., Kaczmarek, Z. (2010): In vitro induction of polyploidy by colchicine treatment of shoots and preliminary characterisation of induced polyploids in two Miscanthus species. - Ind Crops Prod 32: 88-96.

[11] Giusti, M. M., Wrolstad, R. E. (2001): Characterization and Measurement of Anthocyanins by UV-Visible Spectroscopy. - In: Wrolstad, R. E. (ed.) Current Protocols in Food Analytical Chemistry. John Wiley \& Sons, New York.

[12] Hannweg, K., Visser, G. de Jager, K., Bertling, I. (2016): In vitro-induced polyploidy and its effect on horticultural characteristics, essential oil composition and bioactivity of Tetradenia riparia. - S Afr J Bot 106: 186-191.

[13] Kapłan, M., Najda, A., Klimek, K., Borowy, A. (2019): Effect of gibberellic acid (GA3) inflorescence application on content of bioactive compounds and antioxidant potential of grape (Vitis L.) 'Einset seedless' berries. - S. Afr. J. Enol. Vitic. 40(1). DOI: http://dx.doi.org/10.21548/40-1-3004.

[14] Lavania, U. C. (2005): Genomic and ploidy manipulation for enhanced production of phyto-pharmaceuticals. - Plant Genetic Resources 3(2): 170-177.

[15] Murashige, T., Skoog, F. (1962): A revised medium for rapid growth and bioassay with tobacco tissue cultures. - Physiol. Plant. 15: 473-497.

[16] Noori, S. A. S., Norouzi, M., Karimzadeh, G., Shirkool, K., Niazian, M. (2017): Effect of colchicine-induced polyploidy on morphological characteristics and essential oil composition of ajowan (Trachyspermum ammi L.). - Plant Cell Tiss Organ Cult. 130: 543-551.

[17] Oyaizu, M. (1986): Studies on product of browning reaction prepared from glucose amine. - Japanese Journal of Nutrition 44: 307-315.

[18] Özden, M., Özden, A. N. (2014): Comparison of different coloured fruits in terms of total anthocyanins total phenolics and total antioxidant capacity. - Electronic Journal of Food Technologies 9(2): 1-12.

[19] Predieri, S. (2001): Mutation induction and tissue culture in improving fruits. - Plant Cell, Tissue and Organ Culture 64: 185-210.

[20] Prieto, P., Pineda, M., Aguilar, M. (1999): Spectrophotometric quantitation of antioxidant capacity through the formation of a phosphomolybdenum complex: specific application to the determination of vitamin E. - Analitical Biochemistry 269(2): 337-341. 
[21] Ramadan Hassanien, M. F. (2011): Physalis peruviana: a rich source of bioactive phytochemicals for functional foods and pharmaceuticals. - Food Reviews International 27: 259-273.

[22] Ramadan, M. F., Mörsel., J. T. (2007): Oil goldenberry (Physalis peruviana L.). - Journal of Agricultural Food Chemistry 51: 969-974.

[23] Shafiq, M., Qadir, A., Ahmad, S. R. (2019): Biofortification: a sustainable agronomic strategy to increase selenium content and antioxidant activity in garlic. - Applied Ecology and Environmental Research 17(2): 1685-1704.

[24] Slinkard, K., Singleton, V. L. (1977): Total phenol analysis: automation and comparison with manual methods. - American Journal of Enology and Viticulture 28: 49-55.

[25] te Beest, M., Le Roux, J. J., Richardson, D. M., Brysting, A. K., Suda, J., Kubesova, M., Pysek, P. (2012): The more the better? The role of polyploidy in facilitating plant invasions. - Ann Bot 109: 19-45.

[26] Urwin, N. A. R., Horsnell, J., Moon, T. (2007): Generation and characterisation of colchicine-induced autotetraploid Lavandula angustifolia. - Euphytica 156: 257-266.

[27] Valdenegro, M., Fuentes, L., Herrera, R., Moya-León, M. A. (2012): Changes in antioxidant capacity during development and ripening of goldenberry (Physalis peruviana L.) fruit and in response to 1-methylcyclopropene treatment. - Postharvest Biology and Technology 67: 110-117.

[28] Zhang, X. Y., Hu, C. G., Yao, J. L. (2010): Tetraploidization of diploid dioscorea results in activation of the antioxidant defense system and increased heat tolerance. - Journal of Plant Physiology 167(2): 88-94.

[29] Zhishen, J., Mengcheng, T., Jianming, W. (1999): Determination of flavonoid contents in mulberry and their scavenging effects on superoxide radicals. - Food Chemistry 64: 555559 . 